\title{
Nanoengineered implant as a new platform for regenerative nanomedicine using 3D well-organized human cell spheroids
}

This article was published in the following Dove Press journal:

International Journal of Nanomedicine

12 January 2017

Number of times this article has been viewed

\author{
Laetitia Keller ${ }^{1,2, *}$ \\ Ysia Idoux-Gillet ${ }^{1,2, *}$ \\ Quentin Wagner ${ }^{1,2, *}$ \\ Sandy Eap ${ }^{1,2, *}$ \\ David Brasse ${ }^{3}$ \\ Pascale Schwinté 1,2 \\ Manuel Arruebo 4 \\ Nadia Benkirane-Jessel 1,2 \\ 'INSERM (French National Institute \\ of Health and Medical Research), \\ "Osteoarticular and Dental \\ Regenerative Nanomedicine" \\ Laboratory, UMR II09, Faculté de \\ Médecine, FMTS, ${ }^{2}$ University of \\ Strasbourg, Faculté de Chirurgie \\ Dentaire, ${ }^{3}$ CNRS (Centre National \\ de la Recherche Scientifique), \\ UMR 7I78, IPHC (Hubert Curien \\ Multidisciplinary Institute), \\ Strasbourg, France; ${ }^{4}$ Department of \\ Chemical Engineering, INA (Aragon \\ Nanoscience Institute), University \\ of Zaragoza, Zaragoza, Spain \\ *These authors contributed equally \\ to this work
}

\begin{abstract}
In tissue engineering, it is still rare today to see clinically transferable strategies for tissue-engineered graft production that conclusively offer better tissue regeneration than the already existing technologies, decreased recovery times, and less risk of complications. Here a novel tissue-engineering concept is presented for the production of living bone implants combining 1) a nanofibrous and microporous implant as cell colonization matrix and 2) 3D bone cell spheroids. This combination, double 3D implants, shows clinical relevant thicknesses for the treatment of an early stage of bone lesions before the need of bone substitutes. The strategy presented here shows a complete closure of a defect in nude mice calvaria after only 31 days. As a novel strategy for bone regenerative nanomedicine, it holds great promises to enhance the therapeutic efficacy of living bone implants.
\end{abstract}

Keywords: bioengineering, implants, osteoblasts, matrix mineralization, microtissues

\section{Introduction}

In the last two decades there has been considerable development in tissue repair, through tissue-engineering techniques and sophisticated biomaterials. These developments do not only aim at producing substitutes for damaged organs but also participate in the development of regenerative medicine in order to restore tissue function. In particular, there has been increasing interest in developing smart scaffolds mimicking the extracellular matrix, in order to favor long-term cell grafting. ${ }^{1}$ Structural design of biomimetic scaffolds has been improved at the micro- and nanoscale using designed nanostructures, from nanofibers, ${ }^{2,3}$ to nanogrooves, ${ }^{4,5}$ and using different nanomaterials such as carbon nanotubes ${ }^{6,7}$ and graphene material. ${ }^{8,9}$ Nanotechnologies like nanoparticles or nanoreservoirs have also been introduced for the bioactivation of the scaffolds through the controlled release of bioactive therapeutics. ${ }^{10-15}$

During the consolidation of a fracture, or during the continuous physiological bone remodeling, bone regeneration takes place. Medical applications for tissue-engineered (TE) bone implants can be divided into four categories. 1) Bone fracture: $10 \%$ of the bone fractures (1.5 million patients per annum worldwide) cannot be treated by standard therapies (autogenous, allogeneic, and xenogeneic grafts) because the damaged sites are too large. ${ }^{16}$ 2) Spinal fusion: some bone tissue from the patient himself or from a donor, is combined with the natural bone formation to fuse the vertebrae. This procedure, by causing immobilization of the vertebrae, enables elimination of the pain caused by their abnormal motion. ${ }^{17,18} 3$ ) Sinus lift: in dentistry the loss of upper back teeth results over time in some bone shrinkage or resorption in the corresponding area,
Correspondence: Nadia Benkirane-Jessel; Pascale Schwinté INSERM (French National Institute of Health and Medical Research), "Osteoarticular and Dental Regenerative Nanomedicine" Laboratory, UMR II09, Faculté de Médecine, FMTS, F-67085, Strasbourg Cedex, France Tel +33368853376 Email nadia.jessel@inserm.fr; pschwinte@unistra.fr 
as a consequence, the sinuses will expand in the empty space left by the bone loss. A sinus lift is required to place a dental implant to provide the needed space for introducing additional bone in that area. ${ }^{19,20}$ 4) Alveolar ridge augmentations: these consist of surgical bone grafting procedures for patients suffering from bone loss in the upper jaw. The number of patients in this field amounts to approximately 4.5 million per annum worldwide. ${ }^{21-25}$ Among these clinical applications, some require the use of filling the defect by the means of bone substitutes to mimic mechanical properties of bone. The regenerative medicine domain aims to regenerate bone in the case of early lesions with biomaterials close to physiological environment of bone. These biomaterials will be used to prevent and to avoid the necessity of bone substitutes. In this case bone mechanical properties are not required.

In bone tissue engineering, natural biomaterials (such as collagen and cellulose) or synthetic ones (such as metals and ceramics) have been evaluated for their applicability to improve the bone healing process. ${ }^{24}$ First-generation implants mostly comprised metal materials (eg, dental titanium implants) and were created to restore the function of the injured tissue. Unfortunately, over time they often led to inflammation and infection, were subject to joint loosening process, and failed to achieve proper cell adhesion. Later, a second generation of implant biomaterials emerged, on the basis of the use of welltolerated nontoxic medical grade-labeled materials containing a bioactive component to induce a specific cell response, such as hip prostheses coated with the osteoconductive hydroxyapatite. However, such implants are not completely integrated within living tissues, as they do not induce efficient cell adhesion and are still subjected to detachment. ${ }^{26}$ The third generation, now under investigation, focuses on hybrid and nanostructured materials. Those bioactive materials incorporate inert nanostructured scaffolds and living cells to engineer living biomaterials capable of guiding bone healing. ${ }^{25}$

The bone regenerative nanomedicine market is a new niche applying biomimetic scaffolds, growth factors, and/or cells to restore living tissues in the case of small early lesions as preventive nanomedicine. In this manuscript we will describe the use of nanofibrous and microporous scaffolds and human primary bone cells. For the achievement of damaged tissue reconstruction and functional recovery, cell-based tissue-engineering therapies require the presence of $3 \mathrm{D}$ scaffolds to boost the regenerative potential of autologous primary cells or stem cells. These 3D scaffolds require perfectly defined tunable structural and mechanical properties to achieve this purpose. A large number of scientific researches have been focused on the development of 3D scaffolds for specific tissue applications, using fabrication techniques such as electrospinning, microfabrication, lithography, or self-assembly. ${ }^{27}$ Next-generation implants target robust, durable, and rapid tissue regeneration. The double 3D advanced implants reported here are 3D "nest-egg-like", thick nanofiber-based implants seeded with 3D living human microtissues (MTs) rather than single cells. It has been established that the efficiency of $3 \mathrm{D}$ living cells in tissue engineering is related to their capacity to mimic the embryonic development, and reproduce physiological properties. ${ }^{28,29}$

The actual needs of the regenerative medicine field are not only to increase the speed of bone regeneration but also to use non-animal-origin compounds. Collagen membranes clinically used today are unfortunately of animal origin. We report here a new approach in bone tissue regeneration resulting in a superior bone mineralization in a nude mice calvaria defect model, combining 3D nanofibrous poly ( $\varepsilon$-caprolactone) (PCL) material (US Food and Drug Administration-approved synthetic polymer for clinical use $)^{15,30}$ together with preformed well-organized 3D bone MTs derived from human primary osteoblasts (OBs). This sophisticated double 3D strategy could enhance the efficacy of therapeutic implants without adding bioactive molecules. By combining this 3D nanofibrous implant with preformed tridimensional bone MTs derived from $\mathrm{OBs}$, we have recently reported in a short communica$\operatorname{tion}^{31}$ that it is possible to achieve a more efficient bone regeneration than when using just single cells. In this work we have characterized in detail the new bone formation with additional characterization techniques, to validate the concept.

\section{Materials and methods Electrospinning}

The poly ( $\varepsilon$-caprolactone) nanofibrous scaffolds were fabricated with a standard electrospinning apparatus (ECDIG; IME Technologies, Geldrop, the Netherlands). PCL, analytical grade (Perstorp AB, Perstorp, Sweden) was dissolved in dichloromethane/dimethylformamide $(40 / 60, \mathrm{v} / \mathrm{v})$, $27 \%(\mathrm{w} / \mathrm{v})$ and stirred overnight before use. The PCL solution ( $5 \mathrm{~mL}$ syringe) dispensed at a flow rate of $1.2 \mathrm{~mL} / \mathrm{h}$ (ProSense pump) was ejected through a $21 \mathrm{G}$ needle $(0.8 \mathrm{~mm}$ outer diameter), undergoing an electric potential difference. The fiber collector was placed at $16 \mathrm{~cm}$ height from the needle, a voltage of $+15 \mathrm{kV}$ was applied on the needle, and $-5 \mathrm{kV}$ was applied on the collector during the electrospinning process. The electrospun fiber jet was projected into a localized hole (diameter of $25 \mathrm{~mm}$ ) drilled in a poly(methyl methacrylate) mask (2.5 mm thick) placed over the conductive collector. ${ }^{30}$

\section{Scanning electron microscopy}

The electrospun PCL scaffold was gold-coated (Edwards Sputter Coater) and examined under a scanning electron 
microscope (SEM; Hitachi TM1000) operating in conventional mode (high vacuum).

\section{Cell culture}

OBs from PromoCell GmbH (Heidelberg, Germany) were grown in a specific OB growth medium (PromoCell) containing supplement mix (PromoCell) and incubated at $37^{\circ} \mathrm{C}$ in a humid atmosphere with $5 \% \mathrm{CO}_{2}$. Cells, when reaching subconfluence, were harvested with trypsin and subcultured.

\section{Microtissue culture}

For the formation of microtissues (MTs), OB cells were seeded in GravityPLUS ${ }^{\mathrm{TM}}$ plates (InSphero AG, Zürich, Switzerland) at a density of $2.5 \times 10^{5}$ cells $/ \mathrm{mL}$. Each MT was formed from $1 \times 10^{4}$ cells and was grown for 5 days. For in vitro studies and in vivo implantations OB-MTs were then collected and seeded onto the PCL scaffolds.

\section{Cell viability and proliferation}

A total of $4 \times 10^{4} \mathrm{OB}$ single cells were seeded on top of PCL scaffolds deposited in 48-well plates $(n=3)$ and four OB-MTs of $1 \times 10^{4}$ cells each were seeded onto other PCL scaffolds for comparison $(n=3)$. After 3 days of culture, the plates were incubated in 10\% AlamarBlue ${ }^{\circledR} /$ Dulbecco's Modified Eagle's Medium (Thermo Fisher Scientific, Waltham, MA, USA) solution, in a humid atmosphere at $37^{\circ} \mathrm{C}$ and $5 \% \mathrm{CO}_{2}$. After 4 hours, $200 \mu \mathrm{L}$ of incubation medium from each well was transferred to 96-well plates and measured at 570 and $630 \mathrm{~nm}$ to calculate the percentage of AlamarBlue reduction. The same protocol was applied again at 14 and 21 days to study cell proliferation.

\section{In vitro mineralization analysis}

After 28 days of culture, these samples were incubated for 20 minutes in Alizarin Red staining solution (2\%, w/v) and rinsed several times with distilled water. The samples were then embedded in Tissue-Tek ${ }^{\circledR}$ optimum cutting temperature (OCT) Compound and cut in $35 \mu \mathrm{m}$ thin sections using a cryostat (Leica Jung CM3000), for observation under optical microscope (Leica DM4000 B).

\section{Confocal microscopy}

OBs or OB-MTs were seeded onto PCL electrospun scaffolds and grown for 1, 3, or 21 days. After fixation of the samples with paraformaldehyde $4 \%$, cell nuclei were stained using 200 nM 4',6-diamidino-2-phenylindole(DAPI) solution (Sigma-Aldrich Chimie S.a.r.1., Lyon, France) and scaffold nanofibers were stained by soaking the scaffold in a fluorescent poly-lysine-fluorescein isothiocyanate solution.
Samples were examined with a confocal microscope Zeiss LSM 700.

\section{Fluorescence microscopy}

After their 5 days of growth in GravityPLUS ${ }^{\text {TM }}$ plates (InSphero), OB-MTs were fixed with 4\% paraformaldehyde solution, permeabilized with $0.1 \%$ Triton X-100, and incubated in Alexa Fluor 546-conjugated phalloidin (Molecular Probes, Fisher Scientific, Illkirch-Graffenstaden, France) for F-actin staining and in $200 \mathrm{nM}$ DAPI solution (Sigma-Aldrich Co.) for cell nuclei staining. Samples were observed under a fluorescence microscope (Leica DM4000 B).

\section{Calvaria defects and in vivo implantation}

Mice experiments were performed in accordance with the current European Union regulations (Directive 2010/63/EU), authorized and controlled by investigator Dr N Benkirane-Jessel (Director of the Osteoarticular and Dental Regenerative Nanomedicine team), holder of an appropriate license for this study from "Préfecture du Bas-Rhin" (number 67-315). All experiments were done in an approved laboratory (the "Animalerie Centrale de la Faculté de Médecine de Strasbourg") with the approval number A 67-482-35 from the Veterinary Public Health Service of the "Préfecture du Bas-Rhin," on behalf of the French Ministry of Agriculture, Department of Veterinary Science. For tissue implantations, all surgery was performed under ketamine and xylazine anesthesia following established protocols, and all efforts were made to avoid or minimize animal suffering. Anesthesia was realized by intraperitoneal injection of ketamine $100 \mathrm{mg} / \mathrm{kg}$ (Virbac Santé Animale; Centravet, Nancy, France) and xylazine $10 \mathrm{mg} / \mathrm{kg}$ (Rompun, ${ }^{\circledR}$ [Bayer Healthcare, Division Animal Health, France] 2\%). After anesthesia, 6-week-old nude mice (Crl: NIH-Foxn1nu; Charles River, L'Arbresle, France) underwent a surgical double implantation in the calvaria: on one side of the calvaria a PCL 3D implant (500 $\mu \mathrm{m}$ thick, $2 \mathrm{~mm}$ of diameter) seeded with hOB single cells, and on the other side a PCL 3D implant seeded with OB-MTs. The calvaria defects ( $500 \mu \mathrm{m}$ deep and $2 \mathrm{~mm}$ in diameter) were drilled in the parietal zone of the skull using a sterile round burr, under irrigation of sterile saline solution, before implantation of the scaffolds. For the whole study, approximately 35 mice were used. After 4 weeks of implantation, mice were sacrificed by intraperitoneal injection of a deadly dose of ketamine and the implants were extracted for further analysis.

\section{In vivo calcein injection}

Injections of calcein in phosphate-buffered saline $(10 \mathrm{mg} / \mathrm{kg}$, Sigma-Aldrich Co.) were performed subcutaneously on mice, 
on the third and tenth days before necropsy. Four weeks after the calvaria implantation, mice were sacrificed and implants extracted. The samples were embedded in Tissue-Tek OCT Compound, frozen at $-20^{\circ} \mathrm{C}$ and cut in sections using a cryostat Leica Jung CM3000. To stain cell nuclei, thin sections were dipped in $200 \mathrm{nM}$ DAPI solution (Sigma-Aldrich) 5 minutes. Sections were mounted using antifading medium and examined under fluorescence microscope.

\section{SEM-EDS X-ray}

The morphology and composition of the various scaffolds were analyzed using a field emission SEM (Inspect ${ }^{\mathrm{TM}}$ F50; FEI, Hillsboro, OR USA) combined with an energy-dispersive $\mathrm{X}$-ray spectrometer (EDS), to map the elemental composition of the samples. The sample surfaces were Pt-sputtered for allowing SEM observation and examined using an accelerating voltage of $10 \mathrm{kV}$ and work distance of $10 \mathrm{~mm}$. Statistical analyses were performed using analysis of variance test $(n=4)$.

\section{Micro-computed tomography (CT) analysis of calvaria defects in nude mice}

Mice were scanned with a X-ray microtomography ${ }^{32,33}$ under light ketamine xylazine anesthesia. Five X-ray examinations were performed (day [D3], D10, D17, D25, and D31 after surgery). For each examination, the animal was centrally positioned in the view field and 768 radiographies were acquired over $360^{\circ}$ at $40 \mathrm{kV}$ and $200 \mathrm{~mA}$. Images were reconstructed by means of a cone-beam reconstruction algorithm, producing real-time 3D imagery of the linear attenuation coefficient with a $0.05 \mathrm{~mm}$ isotropic voxel size. The threshold used to identify bone structures was set at $0.05 \mathrm{~mm}^{-1}$. The volume of the new bone was evaluated as the number of voxels above the threshold inside a region of interest centered on the hole. Bone growth was given as the percentage of bone volume visualized compared to the first measurement performed at D3.

\section{Results}

\section{D porous polymeric material for bone regeneration}

Recently, we reported an excellent bone regeneration after in vivo implantation in mice using electrospun PCL nanofibrous implants (50 $\mu \mathrm{m}$ thick), leading to a complete cell colonization and bone induction inside the implant. ${ }^{15,34}$ This 3D PCL scaffold ${ }^{15,30}$ was produced by the electrospinning technique (Figure 1A). The electrospun nanofiber scaffolds present superposition of thin nanofibrous layers (Figure 1B). This 3D structure leads to high-macroporosity heterogeneously distributed between the stratified nanofibrous layers. ${ }^{30}$ The nanofibers (Figure 1C) composing the superposed layers (Figure 1B) have a very high specific surface area per volume ratio, because of the small diameters of the fibers, resembling the collagen extracellular matrix ${ }^{35}$ (Figure 1C and D). Random interactions between the different deposited nanofiber layers throughout the electrospinning process result in a random distribution of the pore sizes. These exceptional characteristics of nanofibrous implants are required properties for the targeted application ${ }^{15}$ as they mimic the micro- to nanoscale topography of the extracellular matrix, offering high surface area and porosity, thereby favoring cell adhesion, cell in-growth, and vascularization after in vivo implantation. ${ }^{36,37}$ However, to accelerate the bone healing process, a scaffold alone was not sufficient. For bone repair at the early stages, before it becomes necessary to fill the defect with a bone substitute, regenerative nanomedicine can repair and regenerate bone tissue by using not only scaffolds (synthetic or collagen membranes), but also growth factors and cells.

\section{Double 3D implant to increase bone regeneration}

For small lesions intended to be treated by regenerative medicine, and not requiring mechanical replacement of bone tissue, the use of a thick rather than thin PCL electrospun nanofibrous scaffold is not easy to develop for bone regeneration. Indeed, for such lesions a thick scaffold alone or seeded with single cells was not sufficient to achieve colonization deep within the implant. The objective of this study was to accelerate bone mineralization in vitro and in vivo. We used the hOB cells, which will mineralize and express specific markers after seeding on the 3D scaffold. For regenerative medicine, the important point is to have expression of differentiation markers allowing induction of bone formation and mineralization: the faster these markers are secreted, the faster bone is regenerated. Thus here, time of expression prevails on quantity to compare single cells and MTs. This study attempted to increase the speed of bone growth by using OB-MTs (Figure 2) instead of single cells (OBs) as commonly used today. ${ }^{30}$ The formation of TE bone in vitro can be subdivided into two stages: (i) cellular colonization of the scaffold, and (ii) tissue maturation (bone formation) throughout the scaffold. Therefore, we evaluated the cell infiltration capability of single-cell OBs seeded onto the nanofiber scaffold (Figure 3B), and we compared it with OB-MT-seeded constructs after 21 days in culture (Figure 3E). Cell morphology, cell penetration depth, and bone formation were studied. Results did not reveal major 

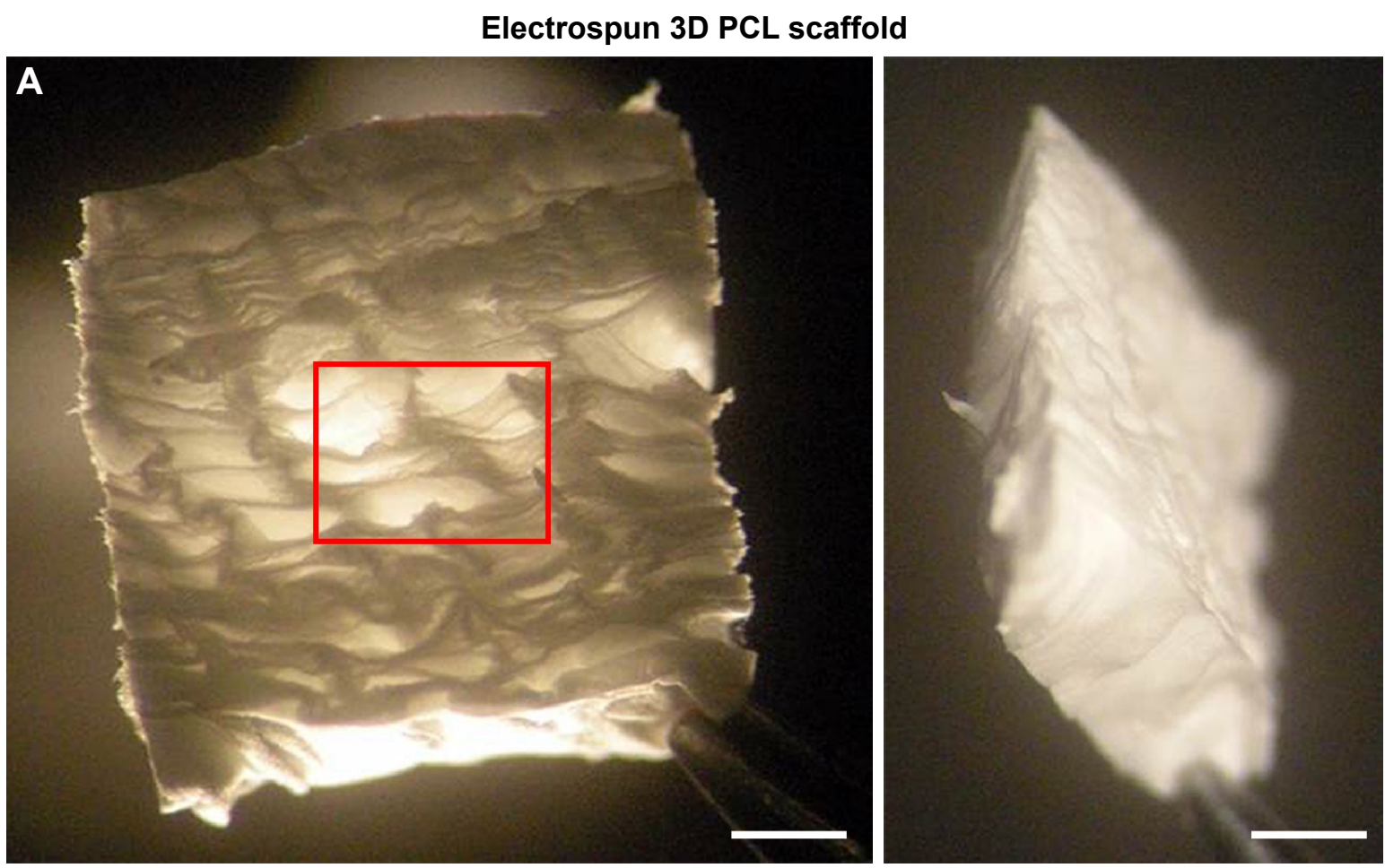

\section{Electrospun 3D PCL scaffold}

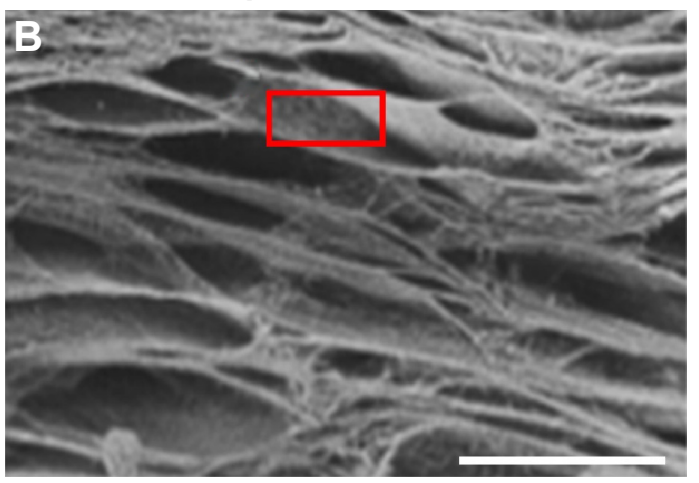

PCL nanofibers

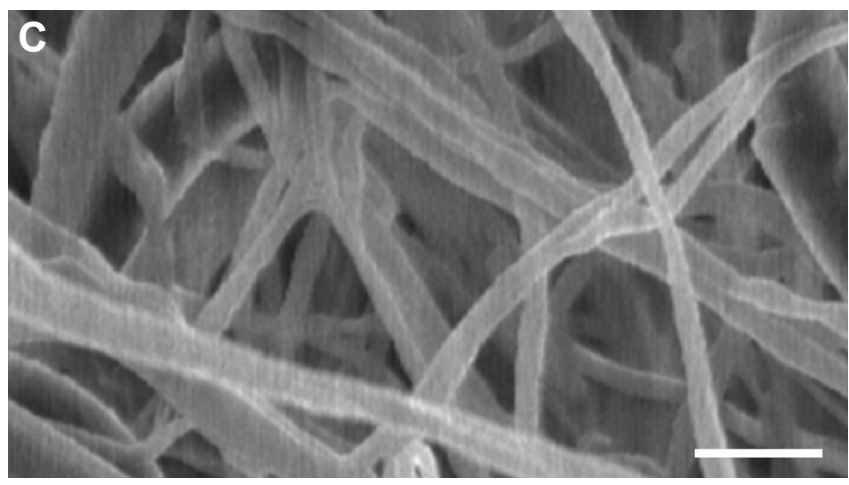

D

\begin{tabular}{|c|c|c|c|}
\hline $\begin{array}{c}\text { Fiber diameter } \\
\text { from C }\end{array}$ & $\begin{array}{c}\text { Pore length } \\
\text { from B }\end{array}$ & $\begin{array}{c}\text { Pore height } \\
\text { from B }\end{array}$ & $\begin{array}{c}\text { Porosity } \\
\text { from A }\end{array}$ \\
\hline $689.1 \mathrm{~nm} \pm 44.9$ & $467.7 \mu \mathrm{m} \pm 44.9$ & $183.3 \mu \mathrm{m} \pm 19.7$ & $93.5 \%$ \\
\hline
\end{tabular}

Figure I Design of 3D electrospun nanofiber scaffold.

Notes: (A) Light micrographs of different views of PCL electrospun 3D scaffold showing a superposition of thin layers made of nanofibers and interconnected macroporosity. (B) SEM observation of the porosity and the thin superposed layers of electropsun PCL constituting the 3D PCL (magnification of inset in A). (C) SEM observation of PCL nanofibers constituting thin layers of scaffold A, showing the nanoscale diameter of fibers (magnification of inset in B). (D) Parameters of the biodegradable 3D PCL membrane: Fiber diameter, pore length and height, and porosity. Porosity was estimated by weight and volume of the sample. Scale bars =I mm (A); $500 \mu \mathrm{m}(\mathbf{B}) ; 2 \mu \mathrm{m}(\mathbf{C})$.

Abbreviations: PCL, poly( $\varepsilon$-caprolactone); SEM, scanning electron microscope.

differences on the surface of the scaffold between OB-MT and $\mathrm{OB}$ groups (Figure 3A, B, D and E). However, staining for calcified tissue by Alizarin Red revealed bone formation in the core of the scaffolds seeded with OB-MTs at 21 days, in vitro (Figure $3 \mathrm{~F}$ ), whereas cell infiltration into the porous structure of the OB-seeded scaffold was rather limited, with a penetration depth in the scaffold of only a few layers, and not present through the entire scaffold (Figure 3C). Actually, this observation may explain why there has been in the past successful treatment of small lesions but only limited success in fully repopulating thicker scaffolds..$^{15,38}$ When seeding with OB-MTs instead of OB single cells, 
A

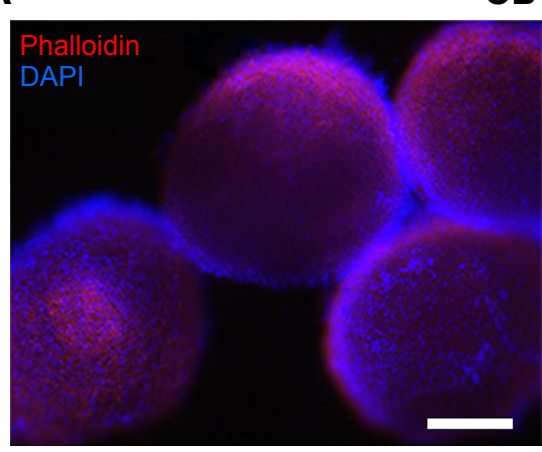

OB-MTs

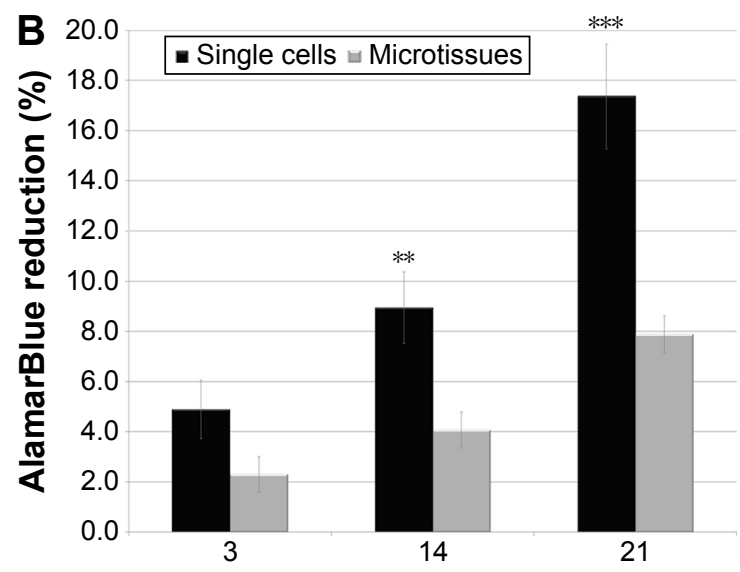

Time (days)

Figure 2 Osteoblastic microtissues formation and biocompatibility with nanofibrous PCL 3D

Notes: (A) Left: fluorescence micrograph of OB-MTs stained in blue with DAPI (showing DNA) and in red with phalloidin (showing actin), just after their formation, before their seeding on 3D PCL. Right: confocal fluorescence microscopy visualization of OB-MTs one day after seeding onto the 3D PCL, and stained in blue with DAPI (showing nuclei) and in green with poly-lysine-FITC (on the nanofibers) leading to visualization of the living microtissue nesting in the implant. (B) Human osteoblasts proliferation seeded onto the 3D electrospun implant. In vitro proliferation of human osteoblasts after seeding with single cells (OBs) or microtissues (OB-MTs) on the thick nanofiber implant after 3,14 , and 21 days. Error bars $(n=3)$. $* * P=0.01$ and $* * * P=0.001$ (analysis of variance). Scale bars $=100 \mu \mathrm{m}$.

Abbreviations: DAPI, 4',6-diamidino-2-phenylindole; FITC, fluorescein isothiocyanate; OB-MTs, human primary osteoblast microtissues; PCL, poly( $\varepsilon$-caprolactone); PLL, poly-lysine.
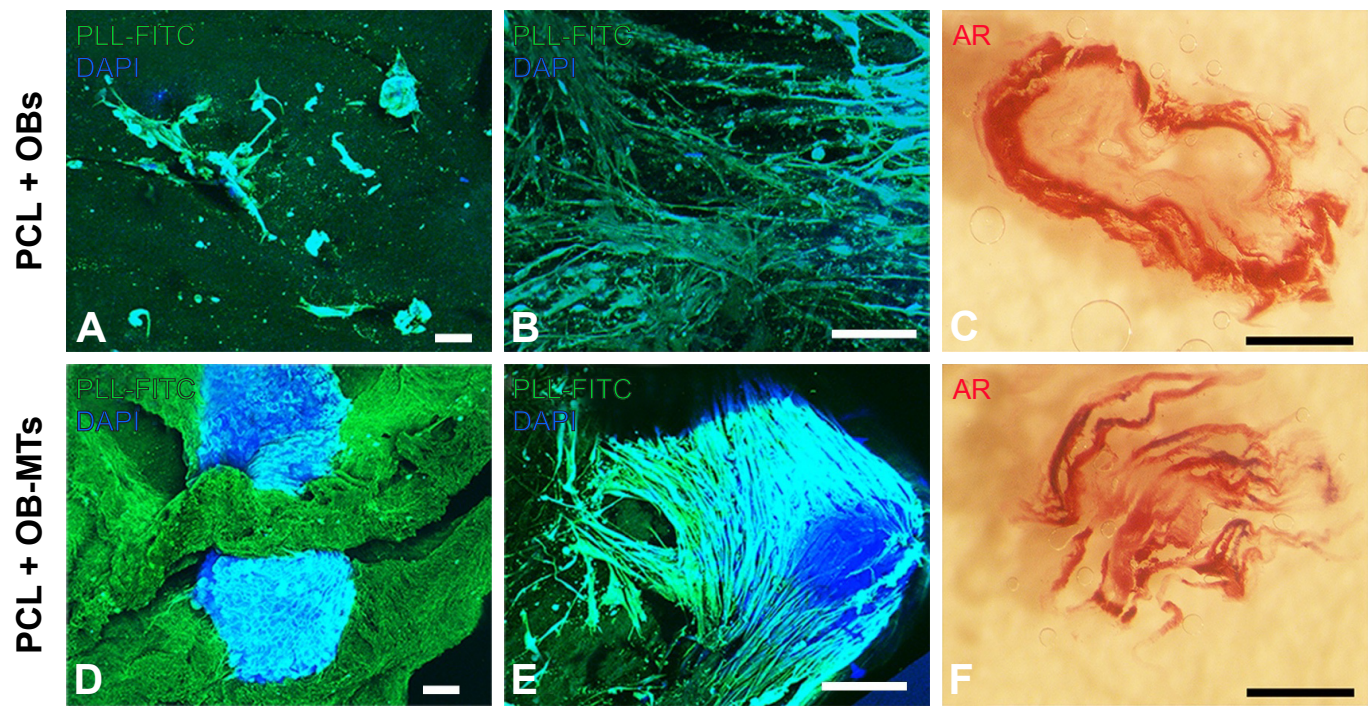

Figure 3 Behavior of osteoblasts seeded on 3D nanofibrous PCL as single cells or as microtissues.

Notes: Fluorescence confocal microscopy visualization (A, B, D, E) of OBs (A, B) and OB-MTs (D, E) grown onto the 3D PCL, and visualized in blue with DAPI (DNA staining) and green with poly-lysine-FITC (nanofibers staining) after 3 days ( $\mathbf{A}$ and $\mathbf{D}$ ) and $2 \mathrm{I}$ days (B and $\mathbf{E})$ in vitro. (C, F) AR of bone induction and mineralization on the 3D thick PCL electrospun nanofiber seeded with OB single cells $(\mathbf{C})$ and OB-MTs (F) after $2 \mathrm{I}$ days. Scale bars $=100 \mu \mathrm{m}(\mathbf{A}, \mathbf{B}, \mathbf{D}, \mathbf{E})$, and I mm $(\mathbf{C}, \mathbf{F})$.

Abbreviations: DAPI, 4',6-diamidino-2-phenylindole; AR, Alizarin Red staining; FITC, fluorescein isothiocyanate; OB, human primary osteoblast; OB-MTs, human primary osteoblast microtissues; PCL, poly(E-caprolactone); PLL, poly-lysine. 
infiltration and bone formation within the core regions of the scaffold were high, as shown by Alizarin Red stain, and interestingly, this was not a result of accelerated cell proliferation, as higher AlamarBlue reduction was observed for the OB-seeded scaffolds throughout the 21-day cell-culture time (more than double at day 21, Figure 2B). After MTs had adhered to the scaffold, cells even began to colonize it after 3 days of culture, showing OB migration along nanofibers (Figure 3A, B, D and E).

With a view to achieve robust bone formation using a thick nanofibrous bone-like implant, we evaluated a novel tissue-engineering concept combining living OB 3D MTs with PCL electrospun nanofiber scaffolds by implanting these grafts in nude mice after creating a calvaria defect. For bone regeneration studies, cranial reconstruction constitutes a very interesting technique, because calvaria is an anatomical bone part undergoing limited mechanical stress, unlike axial skeleton, which withstands compressive loads. ${ }^{39,40}$ A hole of $2 \mathrm{~mm}$ in diameter and $500 \mu \mathrm{m}$ thick was drilled (bone defect) into the domelike superior portion of the mouse cranium. Thus, we investigated the potential improvement of bone formation through incorporation of living OB-MTs into the electrospun thick nanofibrous implant (double 3D strategy). We have followed in vivo bone mineralization onto PCL 3D scaffolds with single OBs (Figure 4A) compared to bone mineralization onto PCL 3D scaffolds with OB-MTs double 3D implants (Figure 4B) 4 weeks after calvaria implantations in nude mice and calcein injection. Our results clearly indicate that more bone mineralization is present when using OB-MTs-seeded scaffolds (Figure 4B).

After confirming superior colonization and mineralization capacity of MT-seeded scaffolds in vitro and in vivo,
OB-MTs only $(n=6)$ and OB-MTs seeded on a PCL scaffold $(n=14)$ were prepared as grafts for a mouse calvaria defect model (Figure 5). For the analysis of bone formation, SEM-EDS X-ray analysis was used to study the kinetics of calcification, in which phosphorous is shown in green, calcium is shown in red, and carbon is shown in blue (Figure 5A). Several random particles from different parts of the sample were selected to perform the SEM-EDS X-ray analysis to obtain a representative average of each sample. The SEM-EDS X-ray maps of the implants displayed a clear colocalization of calcium and phosphorous signals indicating new bone formation (Figure 5A). At 4 weeks postimplantation, $\mathrm{Ca} / \mathrm{P}$ weight ratios were calculated to determine the conversion rate into natural bone. The control bone defect (hole) showed a $\mathrm{Ca} / \mathrm{P}$ ratio of 0.768 , whereas the OB-MTs without scaffold displayed a $\mathrm{Ca} / \mathrm{P}$ ratio of 1.101 . However, the PCL scaffolds loaded with living OB-MTs resulted in a $\mathrm{Ca} / \mathrm{P}$ ratio of 1.701 , indicating hydroxyapatite deposition, in agreement with previous literature. ${ }^{41}$ Statistical analysis showed a highly significant difference between OB-MT groups and PCL+OB-MTs $(P<0.001)$. We also used micro-CT as a noninvasive low-radiation method to assess the bone-defect-healing process in three dimensions (Figure 5B). It produces high-resolution images and permits accurate quantitative analysis of bone structural parameters. The $3 \mathrm{D}$ representation of the bone defect at days $3,10,17,25$, and 31 showed that at day 3 the diameter of the hole was identical between each group (Figure 5B). In the advanced double 3D implant group, the diameter of the defect decreased significantly faster than in the OB-MT group. Quantification of bone growth over 31 days clearly shows an accelerated and more complete bone formation

\section{$\mathrm{PCL}+\mathrm{OBs}$}

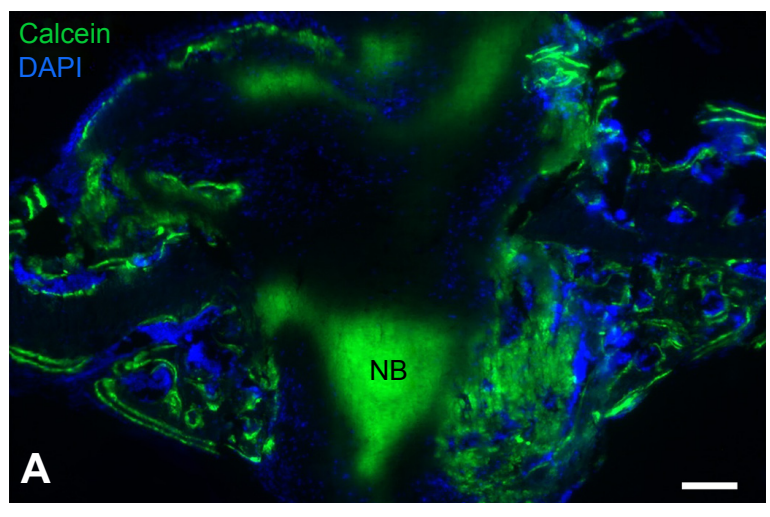

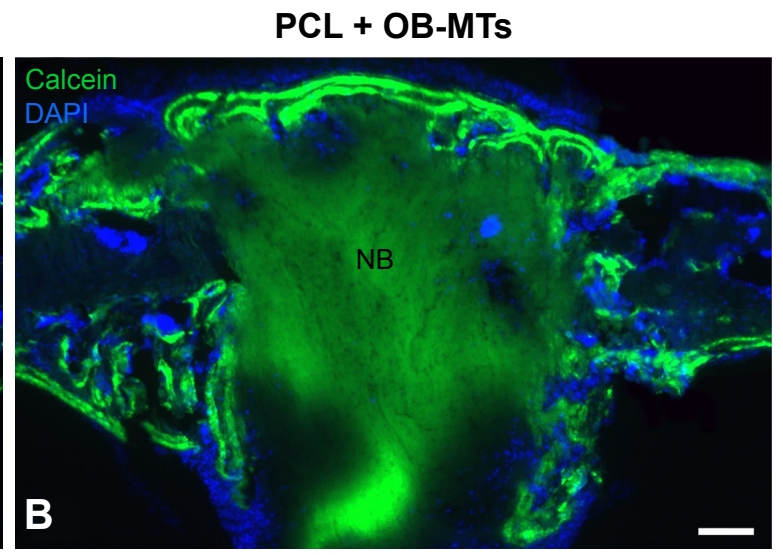

Figure 4 Advantage of using osteoblastic microtissues for bone mineralization and repair (double 3D strategy).

Notes: Implantation of advanced double 3D electrospun nanofiber implants in mice induces bone mineralization. In vivo bone mineralization in PCL 3D seeded with single OBs (A), compared PCL 3D seeded with OB-MTs (B), 4 weeks after calvaria implantations in nude mice. Cell nuclei are labeled in blue, stained with DAPI; bone formation is visualized in green, tainted with calcein. Scale bars $=100 \mu \mathrm{m}(\mathbf{A}, \mathbf{B})$.

Abbreviations: NB, new bone; OB, human primary osteoblast; OB-MTs, human primary osteoblast microtissues; PCL, poly( $\varepsilon$-caprolactone). 


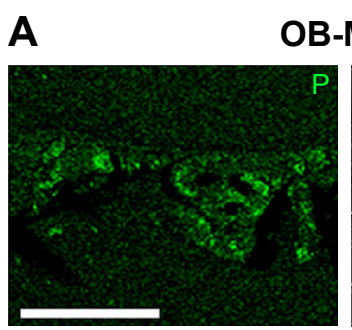

OB-MTs
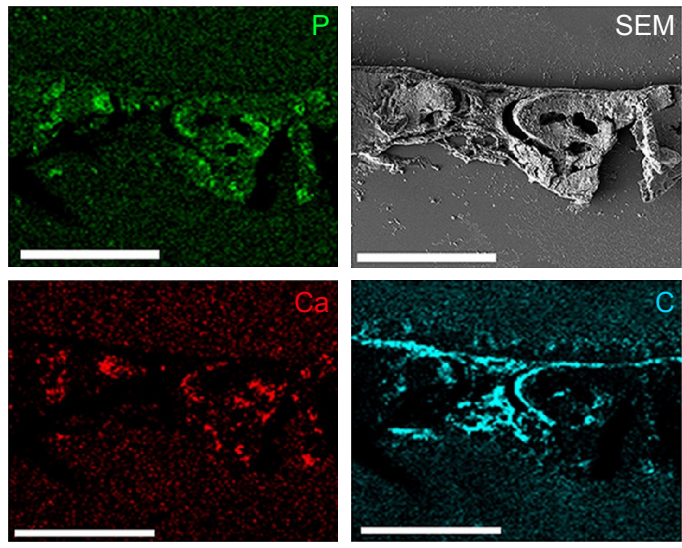

PCL + OB-MTs
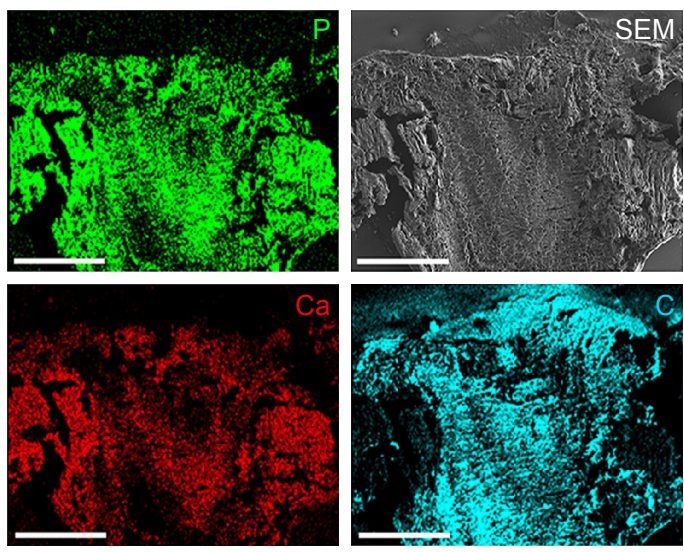

B
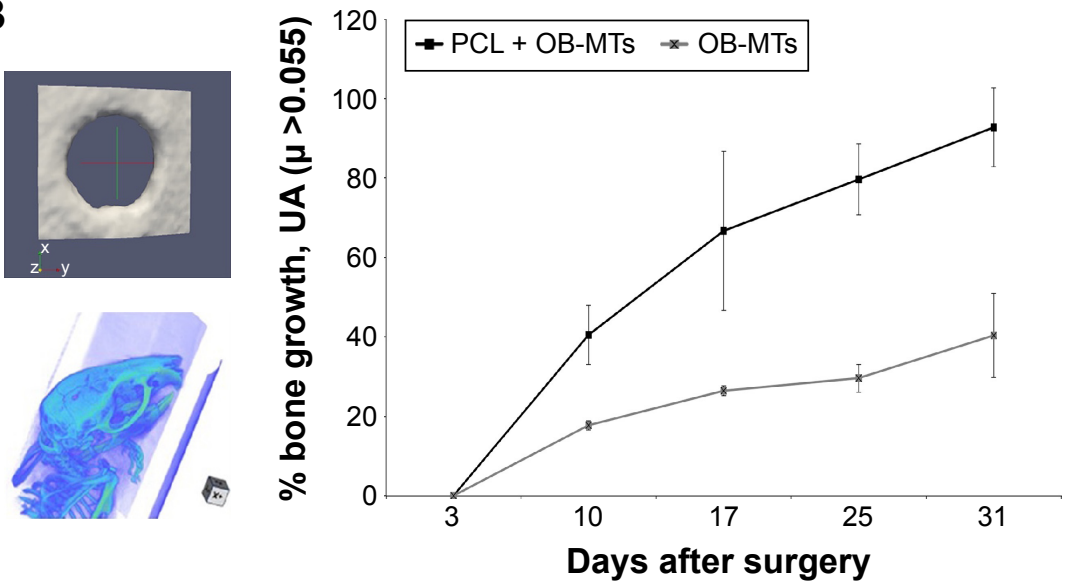

Figure 5 OB-MTs seeded onto the 3D electrospun thick implant (double 3D strategy) and bone regeneration analysis.

Notes: (A) SEM micrographs and SEM-EDS X-ray maps showing the elemental composition as well as morphology of the grafts 4 weeks after implantation in mice calvaria. OB-MTs loaded with 3D PCL or alone. Elemental mapping of phosphorous (green), calcium (red), and carbon (blue) is depicted. Visualization of the grafts by SEM (gray). (B) Micro-computed tomography (micro-CT) analysis. 3D representation of the drilled hole at day 3, leading to bone regeneration analysis of two groups of mice. Groupl: hole seeded with OB-MTs. Group 2: hole after implantation of the 3D PCL implant seeded with OB-MTs (double 3D implant). At day 3, the diameter of the holes is identical for each group. In the 3D PCL + OB-MTs group, the diameter of the hole decreased faster than in the OB-MTs group. Scale bars $=400 \mu \mathrm{m}(\mathbf{A})$.

Abbreviations: EDS, energy-dispersive X-ray spectrometer; OB-MTs, human primary osteoblast microtissues; PCL, poly( $\varepsilon$-caprolactone); SEM, scanning electron microscope.

when using the double 3D implant as compared with OB-MT implants without scaffold (Figure 5B).

\section{Discussion}

Current principles of bone tissue engineering focus on the material properties themselves, active molecules, and cells, to accelerate bone repair efficiency. Many groups develop 3D synthetic polymeric biocompatible and biodegradable materials allowing osteoinduction. ${ }^{42-44}$ This 3D environment is favorable to proliferation, cell differentiation, and mineralization, when equipped with a large amount of single cells. The classical tissue-engineering strategy using single dispersed cells on a biocompatible biomaterial has been predominant over the last 20 years. However, more recently, it has been shown that mineralization could be accelerated by using cells in a $3 \mathrm{D}$ conformation (pellet, spheroid, MT). ${ }^{45}$ Our strategy combines both the 3D scaffold and the 3D MTs instead of single cells. These 3D scaffolds are expected to enable cell migration and maturation through their entire thickness as tissue replacement elements. However, this concept has shown its limitations as clinical use of TE grafts is still modest, because of the fact that these grafts do not allow for sufficient and robust bone regeneration and millions of cells are needed to colonize the scaffolds. ${ }^{46}$ Furthermore, the speed of bone regeneration needs to be improved to beneficially impact quality of life of the patients. In light of the huge potential of creating living TE grafts, new concepts have to evolve, which would give a clear benefit to the patient. Here we demonstrate that by combining two different tissue-engineering strategies, PCL nanofibrous scaffolds together with bone MTs, we reach superior bone tissue formation in vitro as well as in vivo, following implantation in a bony defect model without making use of additional growth factors (Figures 4 and 5). 
Two strategies are currently used to improve tissueengineering efficiency: the first is making use of cells, and the second is based on growth factors. For instance, nowadays in surgery, the Medtronic collagen membrane is used and actually simply soaked in highly concentrated BMP-2 (bone morphogenetic protein-2) growth factor solution, to increase bone repair, but this leads to an uncontrolled release and with an excessive dose. In a previous publication, we had ourselves demonstrated that the necessity of a scaffold to improve bone induction as mixed capsules releasing BMP-2 together with embryonic stem cells, without the presence of a scaffold, could not induce bone regeneration, whereas by the additional implantation of a scaffold, bone formation was actually induced. ${ }^{13}$

It has been reported that in terms of survival, growth, and differentiation signals, the $\mathrm{OB}$ cells will secrete specific biomarkers such as BMPs, RANKL, IL-6, and M-CSF. ${ }^{47-50}$ Furthermore, in vivo, biomaterials of third generation (living biomaterials) enable recruitment of cells to help tissue regeneration through paracrine secretion factors. Active biomaterials for bone tissue engineering are based on the use of active molecules or cells to improve their efficiency. In this work, we used OB cells as MTs, instead of single cells, to avoid the use of active molecules. Indeed, by using double 3D environment including well-organized MTs and 3D scaffold, we demonstrated that this combination was sufficient to accelerate mineralization in vitro. The combination of cells and scaffolds providing appropriate biological moieties was the most promising strategy to improve in vivo bone formation. In this work, the effect of MTs on the increase of bone mineralization speed in the double 3D implant could be explained by the 3D configuration, increasing the speed of extracellular matrix and growth factors secretion, specific to bone repair. Additionally, with this strategy, we observed an accelerated mineralization, which was not correlated with cell proliferation. It is consistent with the fact that cell proliferation is not necessarily the major driver for cell infiltration and tissue maturation, and cell infiltration also depends on cell migration ${ }^{51,52}$ (Figure 3). Furthermore, maturation and mineralization occur after proliferation phase when cells exit from proliferative cycle. MTs allow proliferation arrest, by cell contact inhibition, to enter directly into maturation phase, leading to an accelerated mineralization. Mineralization of OB cells requires not only cell-cell but also cell-matrix interactions. ${ }^{53,54}$ By our double 3D strategy, we amplify these two requirements, leading to an accelerated mineralization and more robust bone formation in vitro as well as in vivo. Moreover, single cells or even MTs injection in the absence of a scaffold has the major disadvantage to fail in keeping the transplanted cells inside the defect.
The main point for a tissue-engineering solution to be clinically transferable is the fast and successful maturation of new tissue throughout the scaffold to achieve the healing processes, as shown for the bone, or to replace dysfunctional tissue. Most 3D models provide a combination of a small number of cells with a large amount of scaffold (natural or synthetic), thereby optimizing cell-scaffold interactions; however, in most natural living tissues, cell-cell interactions are the most prominent. ${ }^{55}$ Compared with conventional single-cell suspensions, MTs perfectly mimic native tissues in terms of structural and functional properties. ${ }^{28}$ The differences in bone formation between the two seeding formats are striking. Both in vitro and in vivo, the advanced double 3D implants demonstrated more complete mineralization (Figure 4). Thus, a promising strategy to improve bone formation is to engineer bone in vitro by generating a functional bone implant from a combination of a biomaterial and cells, rather than to implant solely biomaterials. ${ }^{56}$

\section{Conclusion}

Nanostructured biomaterials for surgical implantations are designed as less invasive, resulting in earlier recovery and less risks for postoperative infection or complications. These innovations are expected to improve the quality of life of patients and expectancy, and reduce health care costs. The advanced double 3D bone implant developed here, combining a nanostructured bioactive biomaterial and predifferentiated osteogenic MTs, resulted in superior bone formation in vitro as well as in vivo. On the basis of this result, we suggest that it would be an improvement to reconsider the current tissue-engineering dogma by replacing single cells with MTs for seeding on scaffolds. In combination with further improvements in nanofibrous scaffolds design, we think that the double 3D strategy could lead to a new generation of improved engineered bone grafts, with faster production times and potentially reduced costs. This concept of tissue engineering is not limited to bone and might be applied, for instance, to cardiovascular or skin tissue engineering.

\section{Acknowledgments}

This work was financially supported by the project NanoOSCAR from the "Agence Nationale de la Recherche". NBJ is indebted to Nancy CHU, "Hôpital Central, Chirurgie Orthopédique et Traumatologie" (INSERM to Hospital Interface Contract). We are indebted to Lionel Thomas and Jean-Michel Gallone from the IPHC, Strasbourg, for the micro-CT analysis. We thank Jens Kelm for his collaboration in MTs preparation. We are also indebted to Dr Nadia Messadeq and Jean-Luc Weickert for their help with SEM. We also thank Victor Sebastian and Carlos Cuestas for their 
help with the HRTEM and SEM-EDX analysis, respectively, and Randy Strube for reading the manuscript.

\section{Author contributions}

Study design and conduct: NBJ, PS. Molecular biology experiments and histological analyses: LK, QW, YIG, SE. $\mu \mathrm{CT}$ and biomechanics: DB, SE. SEM-EDX analysis: MA. Drafting and revising manuscript: MA, PS, NBJ, LK, YIG. NBJ takes responsibility for the integrity of the data analysis. All authors contributed toward data analysis, drafting and revising the paper and agree to be accountable for all aspects of the work.

\section{Disclosure}

The authors report no conflicts of interest in this work.

\section{References}

1. Cheng AY, García AJ. Engineering the matrix microenvironment for cell delivery and engraftment for tissue repair. Curr Opin Biotechnol. 2013;24(5):864-871.

2. Dvir T, Timko BP, Kohane DS, Langer R. Nanotechnological strategies for engineering complex tissues. Nat Nanotechnol. 2011;6(1):13-22.

3. Kane R, Ma1 PX. Mimicking the nanostructure of bone matrix to regenerate bone. Mater Today (Kidlington). 2013;16(11):418-423.

4. Metzger W, Schwab B, Miro MM, et al. Induction of osteogenic differentiation by nanostructured alumina surfaces. J Biomed Nanotechnol. 2014;10(5):831-845.

5. Watari S, Hayashi K, Wood JA, et al. Modulation of osteogenic differentiation in hMSCs cells by submicron topographically-patterned ridges and grooves. Biomaterials. 2012;33(1):128-136.

6. Gusić N, Ivković A, VaFaye J, et al. Nanobiotechnology and bone regeneration: a mini-review. Int Orthop. 2014;38(9):1877-1884.

7. Lim JY, Loiselle AE, Lee JS, Zhang Y, Salvi JD, Donahue HJ. Optimizing the osteogenic potential of adult stem cells for skeletal regeneration. J Orthop Res. 2011;29(11):1627-1633.

8. Nayak TR, Andersen H, Makam VS, et al. Graphene for controlled and accelerated osteogenic differentiation of human mesenchymal stem cells. ACS Nano. 2011;5(6):4670-4678.

9. Depan D, Pesacreta TC, Misra RDK. The synergistic effect of a hybrid graphene oxide-chitosan system and biomimetic mineralization on osteoblast functions. Biomater Sci. 2014;2(2):264-274.

10. Zhang S, Uludağ H. Nanoparticulate systems for growth factor delivery. Pharm Res. 2009;26(7):1561-1580.

11. Wang X, Wenk E, Zhang X, Meinel L, Vunjak-Novakovic G, Kaplan DL. Growth factor gradients via microsphere delivery in biopolymer scaffolds for osteochondral tissue engineering. J Control Release. 2009; 134(2):81-90.

12. Fioretti F, Mendoza-Palomares C, Helms M, et al. Nanostructured assemblies for dental application. ACS Nano. 2010;4(6):3277-3287.

13. Facca S, Cortez C, Mendoza-Palomares C, et al. Active multilayered capsules for in vivo bone formation. Proc Natl Acad Sci U S A. 2010; 107(8):3406-3411.

14. Facca S, Lahiri D, Fioretti F, et al. In vivo osseointegration of nanodesigned composite coatings on titanium implants. ACS Nano. 2011; 5(6):4790-4799.

15. Mendoza-Palomares C, Ferrand A, Facca S, et al. Smart hybrid materials equipped by nanoreservoirs of therapeutics. ACS Nano. 2012;6(1): 483-490.

16. O'Keefe RJ, Mao J. Bone tissue engineering and regeneration: from discovery to the clinic - an overview. Tissue Eng Part B Rev. 2011;17(6): 389-392.
17. Lieberman JR, Friedlaender GE, editors. Bone Regeneration and Repair: Biology and Clinical Applications. New York: Springer; 2005.

18. Lewandrowski KU, editor. Advances in Spinal Fusion: Molecular Science, BioMechanics, and Clinical Management. Florida, Boca Raton: CRC Press; 2003.

19. Woo I, Le BT. Maxillary sinus floor elevation: review of anatomy and two techniques. Implant Dent. 2004;13(1):28-32.

20. Schwartz-Arad D, Herzberg R, Dolev E. The prevalence of surgical complications of the sinus graft procedure and their impact on implant survival. J Periodontol. 2004;75(4):511-516.

21. Salgado AJ, Coutinho OP, Reis RL. Bone tissue engineering: state of the art and future trends. Macromol Biosci. 2004;4(8):743-765.

22. Chatterjea A, Meijer G, van Blitterswijk C, de Boer J. Clinical application of human mesenchymal stromal cells for bone tissue engineering. Stem Cells International. 2010;(2010):1-12.

23. Frohlich M, Grayson WL, Wan LQ, Marolt D, Drobnic M, VunjakNovakovic G. Tissue engineered bone grafts: biological requirements, tissue culture and clinical relevance. Curr Stem Cell Res Ther. 2008;3(4):254-264.

24. Daw R, Tonzani S. Biomaterials. Nature. 2009;462(7272):425-425.

25. Amini AR, Laurencin CT, Nukavarapu SP. Bone tissue engineering: recent advances and challenges. Crit Rev Biomed Eng. 2012;40(5):363-408.

26. Hench LL, Polak JM. Third-generation biomedical materials. Science. 2002;295(5557):1014-1017.

27. Kim HN, Jiao A, Hwang NS, et al. Nanotopography-guided tissue engineering and regenerative medicine. Adv Drug Deliv Rev. 2013;65(4): 536-558.

28. Kelm JM, Fussenegger M. Microscale tissue engineering using gravityenforced cell assembly. Trends Biotechnol. 2004;22(4):195-202.

29. Huh D, Hamilton GA, Ingber DE. From 3D cell culture to organs-onchips. Trends Cell Biol. 2011;21(12):745-754.

30. Eap S, Ferrand A, Palomares CM, et al. Electrospun nanofibrous 3D scaffold for bone tissue engineering. Biomed Mater Eng. 2012;22(1-3): 137-141.

31. Keller L, Wagner Q, Offner D, et al. Integrating microtissues in nanofiber scaffolds for regenerative nanomedicine. Materials. 2015;8(10): 6863-6867.

32. Levi B, James AW, Nelson ER, et al. Human adipose derived stromal cells heal critical size mouse calvarial defects. PLoS One. 2010;5(6): e11177.

33. Brasse D, Humbert B, Mathelin C, Rio MC, Guyonnet JL. Towards an inline reconstruction architecture for micro-CT systems. Phys Med Biol. 2005;50(24):5799-5811.

34. Ferrand A, Eap S, Richert L, et al. Osteogenetic properties of electrospun nanofibrous PCL scaffolds equipped with chitosan-based nanoreservoirs of growth factors. Macromol Biosci. 2013;14(1):45-55.

35. Sell S, Barnes C, Smith M, et al. Extracellular matrix regenerated: tissue engineering via electrospun biomimetic nanofibers. Polymer Int. 2007;56(11):1349-1360.

36. Ingavle GC, Leach JK. Advancements in electrospinning of polymeric nanofibrous scaffolds for tissue engineering. Tissue Eng Part B Rev. 2014; 20(4):277-293.

37. Nisbet DR, Forsythe JS, Shen W, Finkelstein DI, Horne MK. Review paper: a review of the cellular response on electrospun nanofibers for tissue engineering. J Biomater Appl. 2009;24(1):7-29.

38. Amini AR, Adams DJ, Laurencin CT, Nukavarapu SP. Optimally porous and biomechanically compatible scaffolds for large-area bone regeneration. Tissue Eng Part A. 2012;18(13-14):1376-1388.

39. Mankani MH, Kuznetsov SA, Wolfe RM, Marshall GW, Robey PG. In vivo bone formation by human bone marrow stromal cells: reconstruction of the mouse calvarium and mandible. Stem Cells. 2006; 24(9):2140-2149.

40. Kelm JM, Breitbach M, Fischer G, et al. 3D microtissue formation of undifferentiated bone marrow mesenchymal stem cells leads to elevated apoptosis. Tissue Eng Part A. 2012;18(7-8):692-702.

41. George A, Ravindran S. Protein templates in hard tissue engineering. Nano Today. 2010;5(4):254-266. 
42. Gerges I, Tamplenizza M, Lopa S, et al. Creep-resistant dextran-based polyurethane foam as a candidate scaffold for bone tissue engineering: synthesis, chemico-physical characterization, in vitro and in vivo biocompatibility. Int J of Polymeric Materials. 2016;65(14):729-740.

43. Siqueira IA, Corat MA, Cavalcanti B, et al. In vitro and in vivo studies of novel poly(D,L-lactic acid), uperhydrophilic carbon nanotubes, and nanohydroxyapatite scaffolds for bone regeneration. ACS Appl Mater Interfaces. 2015;7(18):9385-9398.

44. Pati F, Song TH, Rijal G, Jang J, Kim SW, Cho DW. Ornamenting $3 \mathrm{D}$ printed scaffolds with cell-laid extracellular matrix for bone tissue regeneration. Biomaterials. 2015;37:230-241.

45. Jähn K, Richards RG, Archer CW, Stoddart MJ. Pellet culture model for human primary osteoblasts. Eur Cell Mater. 2010;20:149-161.

46. Jakob M, Saxer F, Scotti C, et al. Perspective on the evolution of cell-based bone tissue engineering strategies. Eur Surg Res. 2012;49(1):1-7.

47. Papachroni KK, Karatzas DN, Papavassiliou KA, Basdra EK, Papavassiliou AG. Mechanotransduction in osteoblast regulation and bone disease. Trends Mol Med. 2009;15(5):208-216.

48. Atkins GJ, Kostakis P, Pan B, et al. RANKL expression is related to the differentiation state of human osteoblasts. J Bone Miner Res. 2003; 18(6):1088-1098.

49. Yoshitake F, Itoh S, Narita H, Ishihara K, Ebisu S. Interleukin-6 directly inhibits osteoclast differentiation by suppressing receptor activator of NF-kappaB signaling pathways. J Biol Chem. 2008;283(17): $11535-11540$
50. Yamashita T, Takahashi N, Udagawa N. New roles of osteoblasts involved in osteoclast differentiation. World J Orthop. 2012;3(11):175-181.

51. Abed E, Moreau R. Importance of melastatin-like transient receptor potential 7 and magnesium in the stimulation of osteoblast proliferation and migration by platelet-derived growth factor. Am J Physiol Cell Physiol. 2009;297(2):C360-C368.

52. Yoon JK, Kim HN, Bhang SH, et al. Enhanced bone repair by guided osteoblast recruitment using topographically defined implant. Tissue Eng Part A. 2016;22(7-8):654-664.

53. Stein GS, Lian JB, Owen TA. Relationship of cell growth to the regulation of tissue-specific gene expression during osteoblast differentiation. FASEB J. 1990;4(13):3111-3123.

54. Lian JB, Stein GS. Development of the osteoblast phenotype: molecular mechanisms mediating osteoblast growth and differentiation. Iowa Orthop J. 1995;15:118-140.

55. Kale S, Biermann S, Edwards C, Tarnowski C, Morris M, Long MW Three-dimensional cellular development is essential for ex vivo formation of human bone. Nat Biotechnol. 2000;18(9):954-958.

56. Huey DJ, Hu JC, Athanasiou KA. Unlike bone, cartilage regeneration remains elusive. Science. 2012;338(6109):917-921.
International Journal of Nanomedicine

\section{Publish your work in this journal}

The International Journal of Nanomedicine is an international, peerreviewed journal focusing on the application of nanotechnology in diagnostics, therapeutics, and drug delivery systems throughout the biomedical field. This journal is indexed on PubMed Central, MedLine, CAS, SciSearch $\AA$, Current Contents $₫ /$ Clinical Medicine,

\section{Dovepress}

Journal Citation Reports/Science Edition, EMBase, Scopus and the Elsevier Bibliographic databases. The manuscript management system is completely online and includes a very quick and fair peer-review system, which is all easy to use. Visit http://www.dovepress.com/ testimonials.php to read real quotes from published authors. 